\title{
10. PERFORMANCE OF THE LANDING-PAD ASSEMBLY ON LEG 124E SEA TRIALS ${ }^{1}$
}

\author{
Hiroshi Matsuoka ${ }^{2}$
}

\section{INTRODUCTION}

This landing-pad assembly (LPA), designed and manufactured by Ocean Research Institute (ORI), University of Tokyo, will be used as a landing device for the "ONDO" tool, which will be deployed on ODP Leg 131 for investigations in the Nankai Trough (see Fig. 1). This tool will be used for continuous in-situ measuring of downhole temperatures within the confines of the conductor casing.

The purpose of the testing was to confirm that the LPA could be successfully deployed through the ODP drill string without hanging up.

\section{TEST PROCEDURE}

At the start of the test, five stands of 5-in. API drill pipe were made up and hung off at the rig floor (approximately 140 $\mathrm{m})$. All test runs were made by lowering the LPA and sinker-bar assembly into the drill pipe using the sand line and coring winch.

\section{SEA TRIALS ON LEG 124E}

\section{Test 1-Two HW Sinker Bars Below LPA}

The LPA tool was picked up, and two heavy-weight (HW) sinker bars (OT 3566), $3 \mathrm{ft}$ in length, each with an air weight of approximately $105 \mathrm{lb}(47.6 \mathrm{~kg})$, were attached below (see Fig. 1). The total wet weight below the LPA, including the standard sinker-bar assembly ( $500 \mathrm{lb}, 227 \mathrm{~kg}$ air weight), was $617 \mathrm{lb}(280$ $\mathrm{kg}$ ). An unsuccessful attempt was made to run the assembly into the drill pipe. The spring portion passed the upper tool joint without any problem but failed to progress down the pipe. It was concluded that more weight would be required to deploy the tool down thousands of meters of drill string.

\section{Test 2-Five HW Sinker Bars Below LPA}

Since the weight of the two HW sinker bars was not adequate to allow deployment down the drill pipe, three additional HW sinker bars were attached below the LPA. This time the total wet weight below the LPA was approximately $891 \mathrm{lb}$ (404 $\mathrm{kg}$ ). The tool went down the drill pipe to a depth of $65 \mathrm{~m}$ below the dual elevator stool (DES). Heavy frictional drag was experienced during this deployment until penetration halted completely. Five additional runs were made with the tool in this configura-

\footnotetext{
${ }^{1}$ Harding, B. W., Storms, M. A., et al., 1990. Proc. ODP, Init. Repts., 124E: College Station, TX (Ocean Drilling Program)

2 Shipboard engineering and scientific parties are as given in the listing of participants preceding the contents.
}

tion. Each time the tool stopped at $65 \mathrm{~m}$ below the DES, or about midway down the ninth joint of drill pipe.

\section{Test 3-Seven HW Sinker Bars Below LPA}

It was apparent after test 2 that still more weight would be required for a successful deployment. In addition, one stand (three joints) of drill pipe was laid down to aid in identifying whether the pipe itself was causing the tool to stop at that point.

Two more HW sinker bars were added to the tool, making a total of seven. The total wet weight below the LPA was now approximately $1073 \mathrm{lb}(487 \mathrm{~kg})$. Two successful runs were made with the tool in this configuration. The tool was deployed to bottom and retrieved without incident. No problems were experienced with the LPA after the addition of adequate weight.

\section{RECOMMENDED DESIGN MODIFICATIONS}

The following minor design problems were identified during the test.

1. Guide rollers on the springs of the landing pads. At the conclusion of test 2 , the LPA was recovered with the spring guide rollers missing. The third test was conducted successfully with no apparent problems associated with the missing roller assemblies. Modifications to improve the strength of the guideroller shaft and bearing are recommended prior to future deployments.

2. Transducer assembly. Upon opening the packing box in Manila, it was found that all the oil had leaked out of the transducer assembly. The screw that holds the cap of the transducer in place apparently had backed out from vibrations experienced during shipment from Japan. Modifications to the locking system are required to prevent a recurrence of this problem.

3. Upper guide-pipe connections. Although the upper guide-pipe connections were each locked with a set screw, they seemed to loosen during the downhole deployment of the tool. It appeared that landing-pad drag during deployment and retrieval had induced rotation of the upper guide-pipe assembly, resulting in loosened connections. Design modifications will be required to prevent this occurrence in the future.

\section{CONCLUSIONS}

The ONDO temperature measurement tool, to be hung below the LPA, is heavy enough so that there should be no problem in deploying the system through the ODP drill string. The design modifications identified should be undertaken before any future testing or operational field deployments are implemented.

Ms 124E-110 
H. MATSUOKA

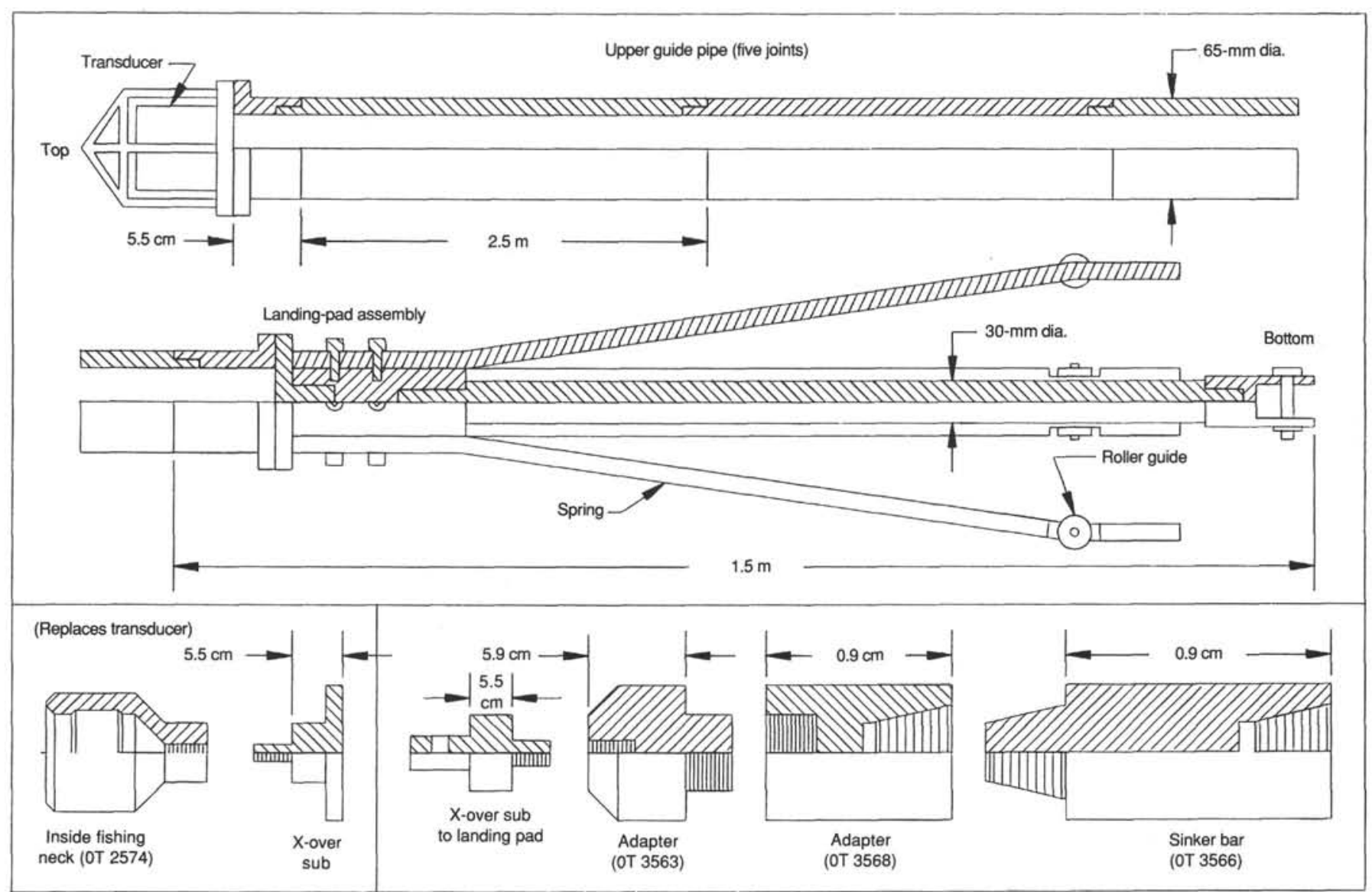

Figure 1. ONDO tool landing-pad assembly, Leg 124E test configuration. 